\title{
Acceso al agua potable y saneamiento: Desafío en las Américas para colectivos étnicos desde los estándares internacionales de protección de los derechos humanos
}

\section{Yennesit Palacios Valencia*}

\section{RESUMEN}

Existe consenso en la comunidad internacional en relación a que el agua y el saneamiento son derechos humanos esenciales, prerrequisitos para el goce de los restantes derechos. Por ello, el derecho internacional de los derechos humanos impone a los estados obligaciones de protección, promoción, respeto y garantía, aplicables también a la defensa de los derechos humanos al agua y el saneamiento. Sin embargo, la realidad actual es preocupante, en tanto que, en las Américas, se han documentado índices elevados de enfermedades, junto con la incorporación de proyectos de extracción minera en ecosistemas de reserva protegida, que transforman el hábitat e inciden negativamente en los recursos hídricos. Esto, sin profundizar en las personas que fallecen por la ausencia de agua potable y saneamiento.

A la par, el panorama es más complejo cuando el estudio se hace desde una perspectiva étnica, en tanto que, personas afrodescendientes, indígenas y tribales, padecen de manera acentuada afectaciones de este tipo en la región. Son personas especialmente vulnerables por la forma diferente en la que habitan y se apropian del territorio. En general, sus rituales ancestrales, entre otros valores culturales, se han visto afectados por la economía del extractivismo que se teje en toda la región.

Este es un panorama aproximado, siendo necesario contextualizar este referente en lo relativo al continente americano, para entender, finalmente, los retos pendientes. Para explicar lo anterior, se presentará un estudio socio-jurídico, basado en el método documental, pero con un enfoque étnico. Este se concentra en poblaciones afrodescendientes, indígenas y tribales y está soportado, entre otras cosas, en reportes e informes emanados del sistema universal e interamericano de protección de los derechos humanos, para comprender las necesidades y exigencias en esta materia, pues preocupa que estos colectivos ocupan un lugar representativo entre las personas que viven en la pobreza y pobreza extrema.

El objetivo central del artículo no solo es visibilizar los desafíos en las Américas para colectivos étnicos desde los estándares internacionales de protección de los derechos humanos, en lo relativo al agua y saneamiento como derechos básicos, sino también, desde un enfoque diferencial étnico/ancestral, reivindicar las particularidades que demandan las poblaciones indígenas, afrodescendientes y tribales, como grupos tradicionalmente excluidos y estigmatizados.

El enfoque étnico es importante, en tanto que, la etnicidad como categoría de análisis permite identificar rasgos distintivos referentes no solo a la herencia africana, sino una cultura propia con necesidades particulares, como el reconocimiento de territorios étnico/ancestrales y su identidad lingüísticocultural.

Puntualmente, el artículo estudia las diversas respuestas conceptuales y jurídicas, relativas a la problemática del agua y el saneamiento en el continente americano, incluidos los enfoques internacionales y sociales, desde diferentes puntos de vista, esto es, las directrices de órganos, organizaciones y organismos internacionales, junto con la perspectiva de los movimientos sociales.

A partir de lo anterior, el artículo se desarrolla en cinco partes así: en la primera, se desarrolla una contextualización de la población objeto de estudio; seguidamente, se explica el planteamiento del problema, asumiendo como tesis central la precariedad del derecho al agua y saneamiento desde una perspectiva étnica. En la tercera parte, se hace un estudio conceptual del derecho humano al agua y saneamiento. En lo que respecta, a la cuarta parte, explica los estándares internacionales de protección de los derechos humanos en esta materia, para entender la responsabilidad de los estados en las Américas y, finalmente, la quinta parte describe los hallazgos y retos pendientes en la región.

Palabras clave

Acceso al agua potable; colectivos étnicos; estándares internacionales, las Américas; saneamiento.

\section{TitLE}

Access to drinking water and sanitation: Challenge in the Americas for Ethnic Groups from International Standards for the Protection of Human Rights

DOI:

https://doi.org//0.15366/relacionesinternacionales2020.45.006

Formato de citación recomendado:

PALACIOS VALENCIA, Yennesit (2020). "Acceso al agua potable y saneamiento: Desafío en las Américas para colectivos étnicos desde los estándares internacionales de protección de los derechos humanos”, Relaciones Internacionales, $n^{\circ} 45$, pp. I37-162.
*Yennesit

PALACIOS

VALENCIA,

Doctora en

Derechos Humanos y

Desarrollo; Máster en

Derechos Humanos,

Interculturalidad

y Desarrollo de la

Universidad Pablo

de Olavide (Sevilla);

Máster en Derecho

Constitucional

del Centro de

Estudios Políticos

y Constitucionales

(Madrid);y

en Relaciones

Internacionales

de la Universidad

Internacional de

Andalucía. Docente

investigadora

- Institución

Universitaria

Tecnológico de

Antioquia. Contacto:

yennesit.palacios@

tdea.edu.co

Recibido:

26/03/2020

Aceptado:

01/06/2020 


\section{Abstract}

There is consensus in the international community that water and sanitation are basic human rights, prerequisites for the enjoyment of the remaining rights. For this reason, international human rights law imposes on States obligations of protection, promotion and guarantee, also applicable to the defense of human rights to water and sanitation. However, the current reality is worrying, while in the Americas, high rates of disease have been documented, along with the incorporation of mining projects in protected reserve ecosystems, which transform habitat and negatively affect resources hydric. This, without delving into the people who die due to the absence of drinking water and sanitation.

At the same time, the panorama is more complex when the study is carried out from an ethnic perspective, since Afro-descendant, indigenous and tribal people suffer afflictions of this type in the region in a marked way and they are especially vulnerable due to the different way in which inhabit and appropriate their territory. In general, their ancestral rituals, among other cultural values, have been affected extractive economy that is woven throughout the region. This aspects have a notable influence on the eradication of the poverty and of certain diseases, especially when Afro-descendant, indigenous and tribal people occupy an important and representative place, among people living in poverty and extreme poverty.

This is an approximate panorama, it being necessary to contextualize this reference in relation to the American continent, to finally understand the pending challenges. To explain the above, a socio-legal study will be presented, based on the documentary method, but with an ethnic focus. This will be supported, among other things, in reports emanating from the universal and inter-American system for the protection of human rights, in order to understand the needs and requirements in this matter, resorting to the special rapporteurs at the United Nations Organization - UN, among them, the Special Rapporteur on the Human Rights to Safe Drinking Water and Sanitation; Special Rapporteur on the Rights of Indigenous Peoples; and the Office of the Rapporteur for the Rights of People of African Descent and against Racial Discrimination, this within the framework of the Organization of American States - OAS.

Reports that are essential for the study, while reaffirming, on the one hand, the importance of safe and universal access to water for all, and on the other, the implications of affirmative actions, based on the principle of equality and non-discrimination, in parallel, in vulnerable populations. In this regard, this document studies the commitments related to human rights in the international field, in light of the standards within the framework of the universal and regional human rights system, using the international corpus iuris issued by the UN and OAS, on the right to water and sanitation.

The main objective of the article is not only to make visible the challenges in the Americas for ethnic groups from the international standards of protection of human rights, in relation to water and sanitation as basic rights, but also, from an ethnic/ancestral differential approach to claim the particularities demanded by indigenous, Afro-descendant and tribal populations, as traditionally excluded and stigmatized groups.

The ethnic focus is important since ethnicity as a category of analysis allows identifying distinctive features referring not only to African heritage, but also to a culture of its own with particular needs, such as the recognition of ethnic/ancestral territories and their linguisticcultural identity.

Specifically, the text studies the various conceptual and legal responses related to the problem of water and sanitation in the American continent, including international and social approaches, from different points of view, that is, the guidelines of organs, organizations, and agencies international, together with the perspective of social movements.

Regarding the human right to water, the article proposes that it should be treated as a social and cultural good, and not fundamentally as an economic good. As an essential element, the human right to water is approached from four perspectives as follows: (I) availability, (2) quality, and (3) accessibility, all of them aligned to (4) the principle of equality and non-discrimination, which for the study, will be addressed independently, but interconnected to the previous ones. Regarding the human right to sanitation, it is approached from the understanding that services must be available and innocuous, acceptable, accessible and affordable.

In this regard, having potable water and sanitation under equitable conditions as an essential component of the enjoyment of all human rights clearly constitutes a responsibility for all States in the region. However, in a continent like the American, characterized by having considerably large cities and very large population, with expansion and development projects that do not limit extractive industries, the situation worsens for the inhabitants of rural areas, who are usually among the poorest.

Based on the above, the article is developed in five parts as follows: in the first, a contextualization of the population under study is developed. On the other hand, in a second moment the problem under study is explained, assuming as a central thesis the precariousness of the right to water and sanitation from an ethnic perspective, that is, in indigenous,Afro-descendant and tribal populations, in the panorama of Latin America and the Caribbean, despite its international recognition as a human right. In the third part, a conceptually comprehensive study is made on the human right to water and sanitation, concluding that, although they are related rights, they are independent and with their own foundations. Regarding the fourth part, it explains the international standards to understand the responsibility of the States in the Americas. Finally, the fifth part describes the findings and pending challenges in the region.

In detail, the close relationship between extractivism, Afro-descendant, Indigenous and Tribal Populations in the region stands out as a conclusion placing some peoples, even in danger of extinction. This a situation that is concentrated, to a greater extent, in the rural context, rather than the urban. This makes it possible to identify, at the same time, a population nucleus more than others, where the right to drinking water and sanitation obviously does not enjoy universality.

Another important and significant finding is the lack of free, prior and informed consent to the indigenous and tribal peoples in the respective governments in the region, prior to the beginning extractive projects on their ancestral land or using resources within the Afrodescendant, indigenous or tribal population's territory.

On the other hand, although the situation of the States in the Americas is very heterogeneous, it is necessary that government policies at the regional level also dialogue with civil society, since these are crucial to reduce environmental degradation and pollution.

\section{KEYWORDS}

Drinking-water access; ethnic groups; international standards, the Americas; sanitation. 


\section{ntroducción}

El agua y el saneamiento son derechos humanos básicos, así ha sido reconocido por la comunidad internacional, en tanto que, son prerrequisitos para el goce de los restantes derechos (ONU, 2010). Por ello, el derecho internacional de los derechos humanos impone a los estados obligaciones de protección, promoción, respeto, y garantía, aplicables también a la defensa del agua y saneamiento. Sin embargo, la realidad actual es preocupante, pues en las Américas se han documentado índices elevados de enfermedades, junto con la contaminación de aguas y la falta de saneamiento básico que afectan a minorías étnicas. Coyuntura que es muy preocupante, máxime cuando personas afrodescendientes, indígenas y tribales, ocupan un lugar representativo entre las personas que viven en pobreza y pobreza extrema en la región. Al respecto,

"aproximadamente 884 millones de personas carecen de acceso al agua potable y más de 2.600 millones de personas no tienen acceso a saneamiento básico y cada año fallecen aproximadamente I,5 millones de niños menores de cinco años y se pierden cuatrocientos cuarenta y tres millones de días lectivos a consecuencia de enfermedades relacionadas con el agua y el saneamiento" (ONU, 20I0, p. 2).

Según la información en la materia,

"de quinientos ochenta millones de habitantes de América Latina y el Caribe, el veinte por ciento no tendría acceso a agua potable por medio de un acueducto y menos del treinta por ciento de las aguas servidas recibirían tratamiento, muchas veces deficiente, resultando que treinta y cuatro de cada I.000 niños mueren cada año en América Latina y el Caribe por enfermedades asociadas al agua (...)" (CIDH, 20I5).

A lo anterior se suma, como agravante, el surgimiento de economías extractivas que incluyen la incorporación de proyectos hidráulicos, extracción minera y forestal, en ecosistemas de reserva protegida que transforman negativamente el hábitat e inciden en los recursos hídricos. Esto, sin profundizar en las personas que fallecen por enfermedades proliferativas asociadas a la ausencia de agua potable y saneamiento.

Este es un panorama aproximado, no obstante, es necesario contextualizar este referente en lo relativo a las Américas, para entender, finalmente, los retos pendientes en la región. Para explicar lo anterior, se presentará un estudio sociojurídico, basado en el método documental, incorporando investigaciones en la materia con enfoque étnico, incluyendo rondas censales y encuestas nacionales de hogares en los últimos diez años. Información que sirve para estudiar las disparidades en el acceso a servicios. El desglose, sin embargo, solo es posible cuando los censos y las encuestas contienen información pertinente acerca del hogar y sus integrantes (JMP, OMS y UNICEF, 20I6).

El estudio también está soportado en reportes e informes procedentes de la Comisión 
Económica para América Latina y el Caribe - CEPAL_-, del sistema universal e interamericano de protección de los derechos humanos, para comprender las necesidades y exigencias en esta materia.

El objetivo central del artículo no solo es visibilizar los desafíos en las Américas para colectivos étnicos desde los estándares internacionales de protección de los derechos humanos, en lo relativo al agua y saneamiento como derechos básicos, sino también, desde un enfoque diferencial étnicoancestral, reivindicar las particularidades que demandan las poblaciones indígenas, afrodescendientes y tribales, como grupos tradicionalmente excluidos y estigmatizados.

Desde una perspectiva poscolonial, el enfoque étnico es importante, en tanto que, la etnicidad como categoría de análisis permite identificar rasgos distintivos referentes no solo a la herencia africana, sino una cultura propia con necesidades específicas, en tanto que, muchas de ellas, son diferentes a las del resto de la población.

En cuanto al derecho humano al agua, el artículo propone que debe tratarse como un bien social y cultural, y no fundamentalmente como un bien económico. El modo en que se ejerza el derecho al agua también debe ser sostenible, acorde a los estándares internacionales en la materia, de manera que, este derecho pueda ser ejercido por las generaciones actuales y futuras.

Como elemento esencial, el derecho humano al agua es abordado desde cuatro perspectivas así: (I) disponibilidad, (2) calidad, y (3) accesibilidad, todos ellos alineados al (4) principio de igualdad y no discriminación que, para el estudio, se abordará de manera independiente, pero interconectado a los anteriores. En lo concerniente al derecho humano al saneamiento, es abordado desde el entendimiento que los servicios estén disponibles y sean inocuos, aceptables, accesibles y asequibles (Consejo de Derechos Humanos, 20I5).

En este contexto el artículo se desarrolla en cinco partes así: la primera hace una contextualización del problema en la población objeto de estudio; seguidamente, se explica el planteamiento del problema, asumiendo como tesis central la precariedad del derecho al agua y saneamiento desde una perspectiva étnica, esto es, en poblaciones indígenas, afrodescendientes y tribales, en el continente americano. En la tercera parte, se hace un estudio conceptual del derecho humano al agua y saneamiento. En lo que respecta, a la cuarta y quinta parte, explican los estándares internacionales de protección de los derechos humanos en esta materia, para entender la responsabilidad de los estados en las Américas y describe, respectivamente, los hallazgos y retos pendientes en la región.

\section{Contextualización del problema en la población objeto de estudio}

La historia revela luchas milenarias sobre la propiedad del agua, los usos conflictivos, la contaminación y el agotamiento de sus fuentes. Lo nuevo es la escala de estos problemas, particularmente, el acceso al agua para los más pobres de los pobres (Langford, 2005) y, en particular, para grupos tradicionalmente excluidos, como lo son, en este caso, poblaciones afrodescendientes, indígenas y tribales, conviviendo en décadas de políticas regionales de desarrollo muy distorsionadas, que se traducen en profundas desigualdades - entre las poblaciones urbana y rural- en lo que se refiere al acceso al agua y sanidad, atención de la salud y acceso a la justicia, entre muchos otros 
derechos humanos (Yamin, 2006).

Sobre el particular, disponer de agua potable y saneamiento en condiciones equitativas como componente esencial del disfrute de todos los derechos humanos (ONU, 20I0), claramente constituye una responsabilidad para todos los estados en la región. Sin embargo, en un continente como el americano, caracterizado por tener ciudades considerablemente grandes y con proyectos de expansión y desarrollo, que no limitan las industrias extractivas, la situación se agrava para los habitantes de las zonas rurales, quienes suelen estar, entre los más pobres, de los pobres (CIDH, 2017), en cada subregión.

Adicionalmente, muchos de estos proyectos no reparan en la protección medioambiental y terminan afectando a poblaciones afrodescendientes, indígenas y tribales en los territorios, y entre estos, a personas campesinas que se han visto obligadas, en algunos casos, a migrar del campo a la ciudad.
"América Latina alberga el $30 \%$ de los recursos de agua dulce del mundo; no obstante, las áreas secas cubren casi un cuarto de la región. Aunque la región tiene solo el $8 \%$ de la población mundial, los efectos del cambio climático a través de sequías e inundaciones, que se están volviendo más frecuentes e intensas, han sido particularmente devastadores para el suministro de agua en las ciudades. Todos estos factores hacen que proporcionar agua potable segura y saneamiento adecuado, sea un desafío para una población que se urbaniza rápidamente" (Calderón, Núñez y Wanner, 2018, p. 6).

Por otra parte, en un panorama general, América Latina y el Caribe - ALC - cuenta con un poco más de seiscientos veinte millones de habitantes y el número de ciudades con más de 500.000 habitantes se ha multiplicado por casi cinco - de veintiocho a ciento treinta y unoen los últimos cincuenta años y más de la mitad de la población urbana - 55\% - reside en ellas (Rojas, 20I4). No obstante,"la seguridad alimentaria, energética e hídrica de la región dependen de los recursos naturales renovables existentes en áreas rurales, entre ellos, el agua, lo que demanda una necesaria complementariedad urbanorural” (Rojas, 20I4, p. 9).

De esa población, se ha identificado que Brasil es el país con una mayor cantidad de personas afrodescendientes, representando más de la mitad de su población - 54\% según datos del Instituto Brasileño de Geografía y Estadística, IBGE-. Le sigue en importancia relativa Cuba, "con un $36 \%$ de personas afrodescendientes, que suman algo más de cuatro millones de personas; y con una proporción menor Colombia, Costa Rica, el Ecuador y Panamá, países en donde la población afrodescendiente representa entre un 7\% y un I0\%" (CEPAL, 20 I7, p. $5 \mathrm{I}$ ). Por otro lado, tampoco se puede desconocer las particularidades de los países del Commonwealth Caribbean —Caribe anglófono'- que tienen, en buena medida, elevados índices de pobreza en la región

\footnotetext{
Belice, Guyana, Jamaica,Trinidad y Tobago, las Islas de Barlovento —Dominica, Santa Lucía, San Vicente y las Granadinas y Granada_, Barbados, las Islas de Sotavento —Antigua y Barbuda, San Cristóbal y Nevis, las Islas Vírgenes Británicas, Anguila y Montserrat-, y las Islas del Norte —las Bahamas, las Islas Caimán y las Islas Turcas y Caicos-.
} 
y una presencia significativa $y$, algunas veces mayoritaria, entre sus poblaciones, de personas afrodescendientes, o mezcla entre indígenas y afrodescendientes, con descendientes de europeos.

En las Américas la diversidad cultural existente, con relación a personas afrodescendientes y pueblos indígenas y tribales es, realmente sorprendente. No solo destaca la riqueza cultural en cada subregión, sino que, al mismo tiempo, estos colectivos pueden tener particulares no siempre coincidentes entre sí. En este caso, la visibilidad estadística viene ganando terreno, producto de las luchas sociales de estos grupos. Pese a esto, todavía faltan muchos otros avances, debido a que dichas particularidades también demandan, en ocasiones, respuestas diversas en los gobiernos de la región.

Nótese que, puede encontrarse un lenguaje común para identificar a personas afrodescendientes, con diferentes categorías según la ubicación geográfica: afrocaribeños, afrouruguayos, afrovenezolanas, afroargentinos, afrocolombianos, afrosurinamese, entre otras. No obstante, no pueden ser categorías homogeneizadoras en cuanto a las necesidades locales y regionales, pues cada país tiene dinámicas y construcciones culturales propias que, en algunos casos, pueden ser coincidentes en la región, en relación con las demandas sociales de estas comunidades por el derecho al agua y saneamiento.

En lo atinente a la visibilidad estadística las rondas censales evidencian, en lo relativo a las personas afrodescendientes, que se ha privilegiado "la perspectiva racial a través de categorías fenotípicas autopercibidas. Esta aproximación, sin embargo, se está modificando en algunos países de la región, en consonancia con el hecho de que algunos grupos raciales adoptan una identidad étnica y la reivindican colectivamente" (CEPAL, 20I7, p. 49).

En Brasil, por ejemplo, subsisten contrahegemónicamente, ragos identitarios propios, cultural y territorialmente, como es el caso de las quilombolas - término reivindicativo asociado a las comunidades afrodescendientes rurales que, aún ligadas al pasado esclavista, se emanciparon y se arraigaron como forma de militancia en lo atinente al reconocimiento étnicoancestral-.

Colombia, por otra parte, desde una perspectiva de derechos, es pionera en la región, pues a través de la Ley 17/1993, otorgó de acuerdo con sus prácticas tradicionales, el reconocimiento a los derechos colectivos de propiedad, demarcación y titulación, sobre las zonas rurales ribereñas de los ríos de la Cuenca del Pacífico, a las Comunidades Negras, Afrocolombianas, Raizales y Palanqueras. Estas últimas, muy puntualmente, en el caso de las Raizales — son descendientes de europeos, africanos e indígenas, y mantienen identidad lingüísticocultural propia-. Las Palenqueras, por su parte, son resultado de procesos emancipatorios de los descendientes de cimarrones antes esclavos- (Castaño, 20I5), que se independizaron y resistieron al sistema colonial en la época de la conquista.

Con este reconocimiento, según la citada Ley, se protege de manera paralela, no solo sus derechos colectivos de propiedad, sino la identidad cultural como grupo étnico y el fomento de su desarrollo económico y social, con el fin de garantizar que estas comunidades obtengan condiciones reales de igualdad de oportunidades frente al resto de la sociedad colombiana. 
El mismo análisis es válido para los casos de Belice, Guatemala, SanVicente y las Granadinas, Honduras y Nicaragua, donde el debate cobra sentido con el grupo étnico garífuna, caracterizado por las raíces indígenas y africanas que subsisten paralelamente. Obsérvese que, "aun cuando el fenotipo de la gente Garífuna es africano, sus características lingüísticas son las de la gente amerindia que habitó las Antillas" (Zapata, s.f., p. 24). También se pueden identificar los creoles o afrocreoles, para el caso de Nicaragua y Honduras, con un dialecto que es una mezcla entre el inglés y lenguas africanas e indígenas.

En el caso de Nicaragua, se identifican comunidades afrodescendientes creole de la RAAS y de la RAAN, que han conservado a través de los años sus costumbres, tradiciones y formas de vida (Jhonson, et. al., 20I2).

Lejos del Caribe aparecen otros rasgos identitarios. Así, en Ecuador, por ejemplo, la Constitución en 2008 dio un paso importante al consagrar, en los artículos cincuenta y ocho y sesenta, el reconocimiento de las nacionalidades y pueblos indígenas,Afroecuatoriano y Montubio, reconociendo expresamente sus derechos sobre el territorio.

De manera general, es claro por los descrito, que las personas afrodescendientes pueden ser identificadas en focos geográfico en cada subregión, que pueden coincidir con patrones de asentamientos históricos que han conducido a que los derechos territoriales formen parte de las reclamaciones afrodescendientes (CEPAL, 2017, p. 57). Sin embargo, en este panorama tan diverso, como diría Wade (2008), reconocer la diferencia puede ser paradójicamente, un medio para ayudar a lograr la igualdad social.

Debido a los procesos migratorios y otras dinámicas de movilidad interna en cada subregión, también es posible encontrar que en los países se ha diversificado su ubicación geográfica y con ellas también sus particularidades y necesidades. Es decir, aunque puede existir predominio geográfico, de unas zonas de asentamientos, más que en otras por sus procesos históricos, también es cierto que en los páises de la región pueden encontrarse tanto en el ámbito rural como urbano.

Por otra parte, focalizando el proceso identitario, en lo relativo a los pueblos indígenas y tribales, es posible afirmar que, su diversidad es tan amplia, como lo son sus necesidades, teniendo en cuenta que muchos de ellos pueden vivir en procesos de aislamientos voluntarios, que también pueden verse truncados por dinámicas propias de modelos de desarrollo extractivistas.

Las comunidades, pueblos y naciones indígenas son aquellas que,

"teniendo una continuidad histórica con las sociedades preinvasoras y precoloniales que se desarrollaron en sus territorios, se consideran distintas de otros sectores de las sociedades que ahora prevalecen en esos territorios, o partes de ellos. Forman actualmente sectores no dominantes de la sociedad y están decididos a preservar, desarrollar y transmitir a las generaciones futuras sus territorios ancestrales y su identidad étnica, como la base de su existencia continua como 
pueblos, de acuerdo con sus propios patrones culturales, sociales instituciones y sistema legal" (UN-DESA, 20I5, p. 4).

No existen datos concretos en relación a la totalidad poblacional en las Américas, no obstante, actualmente es posible contar, aproximadamente, unos ochocientos veintiséis pueblos indígenas en los países de la región, con un panorama altamente heterogéneo:"en un extremo se ubica el Brasil con trescientos cinco pueblos indígenas, seguido por Colombia —ciento dos-, el Perú —ochenta y cinco- y México — setenta y ocho-; en el otro extremo están Costa Rica y Panamá, con nueve pueblos indígenas cada uno, El Salvador — tres_ y el Uruguay — dos_-" (CEPAL, 20I4, p. 44).

En los países de la región con mayor población indígena "-Bolivia (Estado plurinacional de), Guatemala, México y Perú- los pueblos indígenas más numerosos superan ampliamente I,5 millones de personas" (CEPAL, 20I4, p. 44), pero un asunto prioritario, posible de constatar con los censos, "es la fragilidad demográfica de muchos pueblos indígenas, que están en peligro de desaparición física o cultural, hecho que se ha podido observar en el Brasil, Bolivia - Estado plurinacional de-, Colombia y el Perú” (2014, pp. 44-45).

En países de Norte América, los pueblos indígenas tienen un legado histórico importante. En Canadá, por ejemplo, se denominan colectivamente "pueblos aborígenes”. La Ley Constitucional de 1982 reconoce tres grupos de pueblos aborígenes:

"Primeras Naciones, Inuit y Métis. Según el Censo de Canadá de 2016, había I.673.785 aborígenes en Canadá, lo que representa el $4,9 \%$ de la población total, y 977.230 personas declararon que se identificaban como pertenecientes a las Primeras Naciones. Las Primeras Naciones — cuyos pueblos son denominados 'Indians' en la Constitución- comprenden diversas naciones y pueblos que juntos representan más de seiscientas diferentes Primeras Naciones y abarcan más de sesenta idiomas. Los métis constituyen una nación aborigen distinta y su población ascendía a 587.545 en 2016 " (Wessendorf, 2019, p. 70).

Por otra parte, la población indígena en Estados Unidos de América —EEUU—, es comúnmente denominada como grupos nativos. Numéricamente se calcula entre 2,5 y 6 millones de personas, de los cuales el $23 \%$ vive en áreas indias americanas o aldeas nativas de Alaska. De estas, quinientas setenta y tres entidades tribales nativas fueron reconocidas como indias americanas o tribus nativas de Alaska, en julio de 2018 y la mayoría de ellas poseen territorios nacionales reconocidos (Wessendorf, 2019, p. 79). Ahora bien, en las Américas los datos son aproximados, pues hay países que en sus rondas censales todavía no incluyen la pregunta de autorreconocimiento étnico, pese a ello, los avances en la región son muy notorios en este sentido.

Debe resaltarse que, en la región, en algunos territorios de estas poblaciones, las infraestructuras hidroeléctricas, entre otros procesos, "remodelan radicalmente la ecología y el 
medio ambiente de las zonas cercanas. Cuando se realizan de manera inadecuada pueden destruir cadenas alimentarias y provocar desplazamientos masivos de pueblos y comunidades indígenas. Y peor aún, cuando fallan — pueden— producir inundaciones desastrosas” (Berger, 20 I9, p. I I).

Al respecto, la Comisión Interamericana de Derechos Humanos - $\mathrm{CIDH}$ - en el ámbito de la Organización de Estados Americanos -OEA-, ha recibido información preocupante acerca de graves problemas que afectan a los pueblos indígenas y tribales panamazónicos ${ }^{2}$. Se han observado graves afectaciones que resultan de diversos factores: "el impacto producido por normas, políticas públicas y prácticas dirigidas a la extracción y explotación de recursos naturales, así como del desarrollo de megaproyectos de infraestructura o inversión sin consulta ni consentimiento libre, previo e informado" (CIDH, 2019, párr. 2). Proyectos que también están afectando la hidrografía de dichos pueblos, desconociendo el componente ancestral como esencia para su supervivencia. Con todo, los procesos extractivos están presente no solo en la hidrografía de la región, sino en la explotación petrolera, de gas, forestal y minera.

Es más, en lo que respecta al componente tribal — que aplica tanto para poblaciones indígenas como para afrodescendientes - diferenciándose por el hecho de estar organizadas, como su nombre lo dice, en tribus, los fenómenos actuales, que empujan a la migración forzada, entre otros factores, han posibilitado que, en muchas poblaciones, desaparezca el componente tribal, con lo cual, no desaparece la pertenencia étnica —indígena/afrodescendiente-, pero si el hecho de convivir en tribus.

Estudios contrastados demuestran que las poblaciones afrodescendientes, indígenas y tribales, se encuentran ubicadas, en la región, en zonas tanto en el ámbito rural como urbano, donde el acceso al agua potable y el saneamiento es precaria, insuficiente, insalubre o no es asequible en condiciones de igualdad real, por muchos factores que, indiscutiblemente, repercuten en la salud de las personas que habitan en territorios clave, en América Latina y el Caribe.

A nivel subnacional, acorde a una investigación del Banco Mundial (2018), las personas afrodescendientes tienden a estar concentradas en ciertas regiones y ciudades más que en otras, pero estas son, invariablemente, áreas con niveles bajos de desarrollo —lo cual también aplica para las poblaciones indígenas-. Nótese que,

"Típicamente, son regiones con interconexiones precarias con el resto del país y los mercados y, en general, con un menor acceso a los servicios públicos, entre ellos, el acceso al agua potable y saneamiento básico. Algunos ejemplos notables son el norte de Brasil, la costa del Pacíico colombiana, Esmeraldas en Ecuador, Barlovento en Venezuela y las costas atlánticas de Costa Rica, Honduras, Nicaragua y Panamá” (Banco Mundial, 2018, p. 18).

Obsérvese que, según la investigación citada (Banco Mundial, 2018), en Pará, un Estado norteño de Brasil, donde las personas afrodescendientes conforman más de tres cuartas partes

2 Bolivia, Brasil, Colombia, Perú, Ecuador, Ecuador, Guyana, Guayana Francesa, Surinam y Venezuela. 
de la población, uno de cada cuatro hogares carece de acceso a agua potable, mientras que, en Santa Catarina —donde los afrodescendientes representan solo el 16 por ciento de la población, es decir, son minorías-, el acceso al agua corriente es prácticamente universal.

Las brechas de la pobreza permiten observar, desde la óptica del saneamiento y el agua potable, las desigualdades en el nivel de servicio al que acceden los hogares y las tendencias en la cobertura de esos niveles de servicio en el tiempo. En cuanto al saneamiento, este abarca desde la práctica de la defecación al aire libre, el saneamiento no mejorado, hasta el uso de instalaciones mejoradas de saneamiento (JMP, OMS y UNICEF, 20I6).

En el caso de las personas afrodescendientes, como resultado positivo se encuentra, al menos las concentradas en la parte urbana que, las disparidades nacionales en el acceso a servicios básicos, como agua y saneamiento, “no son tan pronunciadas, en relación con los pueblos indígenas u otros grupos rurales vulnerables. Sin embargo, la situación varía enormemente dependiendo del servicio y entre países, así como al interior de ellos" (Banco Mundial, 20 I8, p. I8). Estas diferencias, no obstante, no pueden atribuirse a priori a la discriminación racial, aunque es un indicador que ayuda a determinarla.

\title{
2. Precariedad del derecho al agua y saneamiento en poblaciones indígenas, afrodescendientes $y$ tribales
}

Si se observa de manera general, el panorama en la mayoría de los países andinos (Colombia, Venezuela, Ecuador, Perú, Bolivia, Argentina y Chile), hay quienes afirman que las respectivas legislaciones nacionales, las administraciones y las políticas públicas en el tema de los recursos hídricos suelen negar o ignorar la existencia o la importancia de los marcos normativos consuetudinarios referentes a los derechos y usos consuetudinarios indígenas y a la gestión de los recursos hídricos (Gentes, 2002). Incluso, en aquellos casos en que se toman en cuenta las regulaciones de las comunidades indígenas campesinas locales para gestionar sus sistemas de agua, estos, generalmente,

\begin{abstract}
"se tratan de intenciones más bien estratégicas, pues lo que proponen las políticas públicas según algunas organizaciones indígenas, es institucionalizarlas y tratarlas como cuerpos sociales estáticos, lo que no corresponde a las realidades y costumbres diarias de las comunidades andinas" (Toledo Llancaqueo, 1996, en Gentes, 2002, p. 3).
\end{abstract}

A pesar de lo anterior, se puede observar, según datos de la CEPAL (2019), que la cobertura de estos servicios ha mejorado de manera significativa: en el período 2002-2016, para diecisiete países $^{3}$ de América Latina, el porcentaje de personas con acceso a fuentes adecuadas de agua potable aumentó

"en promedio, 2,8 puntos porcentuales en las zonas

\footnotetext{
3 República Dominicana; Paraguay, El Salvador;Venezuela — República Bolivariana de—, Bolivia, Honduras, Perú, Colombia, Ecuador, Guatemala,
} México, Nicaragua, Brasil, Costa Rica,Argentina, Chile, y Uruguay. 
urbanas y once puntos porcentuales en las zonas rurales. El mismo informe de la CEPAL esclarece que los avances más significativos se dieron en el Brasil, el Perú y Bolivia - Estado plurinacional de-, donde el aumento de la cobertura de fuentes de agua potable en las zonas rurales fue de veintisiete, veinticuatro y veintidós puntos porcentuales, respectivamente. A su vez, el acceso a fuentes adecuadas de saneamiento en las zonas rurales aumentó más de veintidós puntos porcentuales en promedio en el mismo lapso" (CEPAL, 2019. p. I63).

En igual sentido, con base en los datos del Programa Conjunto de Vigilancia - JMP — del abastecimiento de agua y el saneamiento de la Organización Mundial de la Salud - OMS - y el Fondo de las Naciones Unidas para la Infancia — UNICEF_, la región ha avanzado — según un muestreo realizado en veintidós países - "significativamente, en el acceso a los servicios, tanto en agua potable como en saneamiento mejorado, logrando el $94 \%$ de cobertura en el primer caso y $82 \%$ en el segundo" (Rojas, 20 I4, p. II).

No obstante, la realidad es aún, más compleja, de lo que muestran los datos, nótese que, aunque hubo una notable mejoría en ALC entre 1990 y 2015 , algunos países estuvieron en niveles preocupantemente bajos, en cuanto al suministro de agua potable y saneamiento, como Bolivia, Guatemala, Haití o Nicaragua (Bertoméu-Sánchez y Serebrisky, 2018). Además, estas coberturas no precisan que la población goce de servicios con calidad sanitaria garantizada.

De hecho, según ha documentado la CEPAL (20I4), con definición de acceso "seguro y adecuado", la cobertura de agua potable podría ser entre $15-20 \%$ menor y en saneamiento, entre $20-40 \%$ menor, respecto a las estimaciones referidas. Si bien, la metodología de recopilación ha mejorado, las cifras subestiman los problemas por diversas razones:"parte del problema reside en el hecho de que la presencia física de una fuente 'mejorada', como puede ser una letrina de pozo o una fuente de agua, no siempre es un indicador preciso de un acceso mejorado" (PNUD, 2006, p. 37).

Al respecto, a nivel global el informe de las Naciones Unidas sobre el desarrollo de los recuros hidricos de 2019, ratifica que, pese a los esfuerzos,

"el monitoreo global muestra una marcada discrepancia entre las personas que viven en áreas rurales y urbanas. En 20I5, dos de cada cinco personas en áreas rurales tenían acceso a reservas de agua entubada —una forma de suministro 'mejorado' pero, no necesariamente, un suministro 'gestionado de forma segura'-, mientras que cuatro de cada cinco personas en áreas urbanas tenían suministro por tuberías. Las conexiones al alcantarillado predominan en las áreas urbanas, donde son

\footnotetext{
4 Argentina, Barbados, Bolivia —-Estado Plurinacional de_-, Brasil, Chile, Colombia, Costa Rica, Ecuador, El Salvador, Guatemala, Haití, Honduras, Jamaica, México, Nicaragua, Panamá, Paraguay, Perú, República Dominicana, Trinidad y Tobago, Uruguay, Venezuela —República Bolivariana de-
} 
utilizadas por el $63 \%$ de la población, en comparación con solo el $9 \%$ en las áreas rurales (OMS/UNICEF, 20I7a). Sin embargo, la rápida urbanización no siempre mantiene el ritmo de la expansión de los servicios públicos a los más pobres y existe una enorme discrepancia en la prestación del servicio entre las áreas formales e informales de las ciudades" (UNESCO, 2019, p. 44).

Si bien, queda clarificado que, un factor que limita el acceso al agua potable y el saneamiento básico en la región, no menos importante, para el propósito de este estudio, es la pobreza y pobreza extrema, otro elemento esencial para el análisis es el hecho que, estos grupos poblaciones, en ocasiones, no solo son relegados a áreas con acceso limitado a servicios básicos para la vida, sino que están expuestos a niveles mayores de contaminación y a desastres naturales. En este caso se destaca que,

"se estima que para el 2015, I8 millones de personas seguían practicando la defecación al aire libre y 8,5 millones de personas dependían de las aguas superficiales para beber; en siete países, más de un millón de personas practicaron la defecación al aire libre en 20 I5, con el mayor número en Brasil, Colombia y Haití. Por otra parte, en seis países, más de medio millón de personas usaron aguas superficiales para beber en 20I5, con el mayor número en Colombia, Perú y Ecuador. La defecación al aire libre fue practicada por casi la mitad de la población rural en Bolivia en 2015 y uno de cada cinco utilizó aguas superficiales para beber" (JMP, OMS y UNICEF, 2016, p. 3).

Lo descrito es una de las manifestaciones más claras de la pobreza extrema, pero debe decirse que, de estos países, Haití — país afrocaribeño por excelencia- debido a su elevado índice de pobreza en el continente, tiene una dinámica bastante compleja, pues paralelamente ha padecido desastres naturales que agravan la situación.

La población total del país asciende a 8,7 millones de habitantes y cuenta con un $95 \%$ de personas afrodescendientes y el nivel de acceso al agua potable y al saneamiento se ubicaba entre los más precarios de América Latina y el Caribe. En este contexto, en Haití se han exacerbado las necesidades de agua y saneamiento, dado que un gran número de habitantes se vio afectado durante un terremoto en el 2010 (Brackmann, 20I I). Pero al menos, según estudio, "resuelve el problema de la falta de infraestructura de aguas residuales mediante el uso de inodoros secos y el transporte dirigido por la comunidad para producir fertilizantes a partir de desechos humanos" (UNESCO, 2019 , p. 59).

Un acercamiento a otros estados de la región, arrojan por ejemplo, en el Caribe anglófono, como en el caso de Jamaica que, hasta el 2016, una población estimada de 2.970 .340 habitantes donde el $92 \%$ de la población es afrodescendiente- que los problemas sociales como la pobreza, 
la ubicación de asentamientos humanos en zonas de alto riesgo, la degradación del medioambiente y la infraestructura y la vivienda mal construidas, han exacerbado la vulnerabilidad, en lo relativo a su fragilidad por múltiples riesgos naturales y ocasionados por el hombre (Organización Panamericana de la Salud, s.f.).

En el caso de Belice, ubicado en Centro América, su población es multiétnica, lo cual incluye un grupo mayoritario mestizo —-52,9\% - , seguido de los descendientes de africanos - $26 \%$ la etnia garífuna - 6,1\%- y los indígenas mayas - II,3\%-. En este contexto multicultural, la satisfacción de necesidades básicas como el agua potable es muy precaria y entre las poblaciones vulnerables se encuentran quienes viven en condiciones de pobreza, en particular los niños y los ancianos, así como los pueblos indígenas y los afrodescendientes (Organización Panamericana de la Salud, s.f.).

En otro contexto, en América del Sur, países como Surinam donde los afrosurinameses alcanzan aproximadamente el $22 \%$ de la población, se ha caracterizado por deficiencias en temas de seguridad alimentaria y nutricional, razón por la cual la Organización de las Naciones Unidas para la Alimentación y la Agricultura —ONUAA o FAO, en Inglés—, ha identificado cuatro áreas prioritarias: (a) seguridad alimentaria y nutricional; (b) sistemas de inocuidad alimentaria, calidad y certificación; (c) desarrollo de cadenas de valor para el fortalecimiento de los sistemas alimentarios; (d) gestión de recursos naturales, mitigación de desastres y resiliencia (Food and agriculture Organization of the United Nations, s.f.). Recuérdese en este sentido, que el agua es un factor nutricional clave.

Por otra parte, en Costa Rica, al igual que en otros países del continente, "las tierras indígenas fueron tituladas sin un previo proceso de saneamiento y esto continúa generando conflictos, tanto en el interior de los territorios como en sus perímetros". (Parellada, 2019, Pp. 89-90). Estos conflictos se han agravado por la ocupación de tierras por terceros y a la extracción ilegal de recursos naturales, entre los cuales se destacan, el agua $\circ$ la madera, entre algunos ejemplos.

En lo que respecta a Bolivia — Estado plurinacional de- y Perú, países con procesos históricos significativos que vinculan a pueblos indígenas, la situación es similar. Por una parte, en Bolivia durante el gobierno de Evo Morales se desarrollaron grandes obras de infraestructura que han afectado a territorios y comunidades indígenas, junto con la proliferación, al mismo tiempo, de enfermedades como la diarrea, correlativa a la prevalencia de enfermedades de origen hídrico (Gertner, 20l6), por carencia de acceso a fuente de agua segura y saneamiento adecuado.

Por la otra, en Perú hay indicios del surgimiento de posibles normas, a nivel ambiental, que a futuro pueden hacer permisible la práctica del fracking o fracturación hidráulica (Castro, 2018). Un método que desestabiliza la base de los territorios a través de la perforación de material rocoso subterráneo, con el fin de buscar fuentes de combustible (Parellada, 2019). De ponerse en práctica este método, podría causar un perjuicio irremediable sobre la tierra y las fuentes de agua.

Según fuentes, el uso de fracking "ya ha tenido impactos negativos en el territorio peruano, pues esta práctica se encuentra detrás del gran caso de contaminación de las cuencas de los ríos 
Marañón, Tigre, Corrientes y Amazonas” (Parellada, 2019, p. 216).

En Colombia, por ejemplo, la Ley 70 de 1993, expedida con posterioridad a la Constitución de 1991 —que da un enfoque multicultural a la Nación - como un hecho de buena práctica, ha posibilitado titulaciones para territorios colectivos de comunidades afrodescendientes, principalmente en la costa pacífico, facilitando unos ciento treinta y dos títulos, de los cuales ciento dieciséis están ubicados en dicho litoral (Programa de Justicia Global y Derechos Humanos, 2009, párr. I8I). Pero se aclara, que el pacífico colombiano tiene una elevada presencia tanto de indígenas como de afrodescendientes, aunque es mayoritaria en el último caso.

Lo valioso es que la citada ley, permite la fórmula organizativa para la sociedad civil, en consejos comunitarios - grupos étnicos con prácticas propias - con facultad de organizarse políticamente para solicitar el derecho a la propiedad colectiva de las tierras que habitan y administrarlas por derecho propio u originario. Lastimosamente, en este contexto algunos Consejos Comunitarios y activistas han informado, sobre la explotación intensiva y extensiva de los recursos hídricos a causa de la minería.

Un aspecto fundamental a tener en cuenta en los análisis de los impactos de la minería sobre los ecosistemas es la transformación de la calidad del agua que se produce durante las etapas de exploración y explotación del proyecto minero. En la primera fase, como explican Vasquez et. al. (2019),

"la excavación para toma de muestras tiene un alto impacto ambiental muchas veces irreversible, como acidificación de las aguas, inestabilidad de taludes, deforestación y apertura de accesos que generan pérdida de hábitats, biodiversidad y afectación de ecosistemas (Fierro, 20I2). En la segunda, 'durante la explotación los impactos ambientales son más agresivos como la alteración fisicoquímica de las aguas, sedimentación y afectación de la dinámica de los cuerpos de agua por el vertimiento de aguas residuales mineras' (Vasquez, et. al., 2019, pp. 26-27).

Todo lo anterior, sin llevar a cabo procesos de consulta previa, libre e informada, con los pueblos y comunidades afrodescendientes, indígenas y tribales, que habitan en el pacifico colombiano, quienes viven en constante disputa por el creciente interés extractivo, especialmente en el sector minero —aunque no es de menor importancia el extractivismo forestal-, lo cual está afectando su hidrografía y sus costumbres.

Estos procesos, más allá, del contexto colombiano, también impactan de forma irreversible en los sistemas de vida y la identidad cultural de las comunidades indígenas y los ecosistemas amazónicos ( $\mathrm{CIDH}, 2019)$. En este escenario, destacan en la región, además de Colombia;Venezuela, Perú, Ecuador, Bolivia, Surinam, Guyana y Brasil, quienes comparten la Amazonía, actualmente considerada pulmón del mundo. 
Desde esta óptica, con respecto a los recursos hídricos y en consonancia con esta lógica indígena diferente, parece evidente que, al no existir mínimamente sistemas claros de reconocimiento de usos y derechos indígenas, la eventual referencia a sistemas de gestión integral del agua se encuentra muy debilitada (Gentes, 2002).

En el caso puntual, Brasil, según reporta la Comisión Interamericana, "un total de 44.9II proyectos de minería en la Amazonía para 2016, 17.509 incidirían, total o parcialmente, sobre tierras indígenas o unidades de conservación" ( $\mathrm{CIDH}, 2019$, párr. 74). Esto, en un escenario general, es incompatible con la supervivencia de los pueblos que habitan en estos territorios con relación a sus usos y costumbres ancestrales, teniendo en cuenta que también se ve afectado el ecosistema que se teje alrededor de los bosques, ríos, animales y plantas, afectando su estabilidad espiritual y el mismo hábitat.

Por otro lado, según la CEPAL (20/4), de acuerdo con el catastro de conflictos por proyectos de industrias extractivas en territorios indígenas y a partir de la revisión de los informes elaborados por el Relator Especial de Naciones Unidas para los Derechos de los Pueblos Indígenas en el período 2009-2013, es posible distinguir seis nudos de problemas, que en la mayoría de los casos se presentan con distintos grados de imbricación.

Entre estos, se destacan cuatro de ellos esenciales para el estudio, estos son: conflictos por un inadecuado o inexistente resguardo jurídico de los derechos de los pueblos indígenas sobre sus tierras, aguas, recursos naturales, biodiversidad y territorialidad; deficiente o inexistente evaluación independiente del impacto ambiental, social, económico y territorial de los proyectos extractivos. Incumplimiento del deber estatal de consulta con los pueblos indígenas y de adopción de los resguardos y medidas para proteger sus derechos antes de otorgar concesiones o autorizar la ejecución de proyectos extractivos; y exclusión de los pueblos indígenas de la participación en los beneficios por la explotación de recursos de sus territorios (CEPAL, 20I4, p. 58).

Desafortunadamente, en la última década el auge en la demanda internacional de bienes primarios:

"-minerales, hidrocarburos, soja y otros productos básicos agrícolas - se ha traducido en un mayor dinamismo económico en los países de América Latina, pero a costa de un número creciente de conflictos ambientales, sociales y étnicos en torno a las industrias extractivas situadas en territorios indígenas o sus cercanías" (CEPAL, 20I4, p. 58).

En el caso de norte América, países como EEUU y Canadá, tampoco salen bien librados. Al respecto, los Gobiernos de Canadá y Ontario no han desarrollado políticas clave, para reparar los impactos de la intoxicación por mercurio en la Primera Nación Grassy Narrows -pueblos indígenas originarios predominantes-.Aunque el Gobierno de Ontario se comprometió en 2017 a limpiar el sistema fluvial ese mismo año,

"no se ha tomado ninguna medida en ese sentido. No obstante, 
el pueblo de Grassy Narrows sigue trabajando incansablemente en la lucha para exigir cuentas e indemnización por los múltiples impactos culturales y sanitarios de la intoxicación por mercurio que enfrenta su primera nación" (Wessendorf, 2019, p. 74).

Por su parte, en Minnesota -EEUU—, las tribus Ojibwe Red Lake y White Earth, así como también grupos nativos y ecologistas, presentaron apelaciones contra la aprobación de la Comisión de Servicios Públicos del Estado, de un plan para reemplazar un antiguo oleoducto, pues temen que un derrame contaminaría las cabeceras del Mississippi y aguas importantes para la cosecha de arroz salvaje, un alimento tradicional para los Ojibwe (Wessendorf, 2019). Desde lo descrito, nótese que, en un contexto global, pese a los esfuerzos en la región por mejorar dicha situación, esto está provocando la regresividad de los derechos económicos, sociales, culturales y ambientales -DESCA-.

Lo anterior significa que, los estados en las Américas, en gran medida, no han desarrollado políticas públicas de alcance universal, para cubrir necesidades vitales en los territorios de estas poblaciones, o bien, existiendo, estas tienen eficacia simbólica.

En lo que atañe a los derechos humanos de personas afrodescendientes, indígenas y tribales, las necesidades básicas, a la luz de políticas públicas inclusivas, deben tener en cuenta la cosmovisión de estas poblaciones. Para algunas comunidades Afrodescendientes e indígenas, por ejemplo,

"la salud como bienestar biológico, psicológico y social de un individuo equivale a la armonía de todos los elementos que hacen la salud, es decir, el derecho a tener su propio entendimiento y control de su vida y el derecho a la convivencia armónica del ser humano con la naturaleza, consigo mismo y con los demás, encaminada al bienestar integral, a la plenitud y a la tranquilidad espiritual, individual y social" (Procuraduría para la Defensa de los Derechos Humanos, 20I2, p. 4I; Organización Panamericana de la Salud y Organización Mundial de la Salud, 1997, p. 13).

A esto se debe que los problemas derivadas de la contaminación ambiental antrópica o humana, repercuta no solo en la salud sino en sus usos, costumbres y modos de vida, teniendo en cuenta que, en general, una característica importante de comunidades afrodescendientes, tribales e indígenas es estar ubicadas en zonas rurales, ribereñas, pues la vida puede gestarse en torno a los ríos, con actividades como la pesca.

Concluyentemente, lo explicado en este acápite no puede separarse de la afectación a la salud. En Los Estados Unidos, por ejemplo, se ha documentado en el Condado de Lowndes, Alabama, con un promedio de $74 \%$ de afroamericanos y donde casi un tercio de la población vive por debajo del umbral de la pobreza, el anquilostoma, una enfermedad que se creía había 
desaparecido en la década de 1980, está prosperando, en gran parte, debido a la deficiencia de eliminación de residuos sanitarios, pues sus habitantes se lavaban con aguas residuales crudas en sus hogares a partir de tuberías sépticas o de desagüe defectuosas (Riggs, Hughes, Irvin y Leopard, 2017).

En este escenario se constata que el análisis y la interpretación de la situación de salud requieren "por una parte, la contextualización sociopolítica e histórica de estos grupos sociales, y por la otra, la consideración del efecto sinérgico que tienen sobre ella los mecanismos sociales de estratificación estructural, principalmente la posición socioeconómica desfavorable y la discriminación étnica" (CEPAL, 20 I3, p.28). La información disponible muestra una sobremortalidad de estos grupos que puede interpretarse como un indicador de la falta de cumplimiento de sus derechos.

Lo grave, finalmente, es el hecho que las personas que presentan mayor riesgo de contraer enfermedades transmitidas por el agua son los lactantes y los niños de corta edad, las personas vulnerables, quienes viven en condiciones antihigiénicas y los ancianos. Si bien, el agua potable es adecuada para todos los usos domésticos habituales (Organización Mundial de la Salud, 2006), puede necesitarse agua de calidad para casos concretos y para prevenir enfermedades endémicas.

\section{Desarrollo conceptual de los derechos humanos al agua y al saneamiento}

Aunque en el 2020 se cumplen diez años del reconocimiento por parte de la Asamblea General de las Naciones Unidas - AGNU_- en lo relativo al derecho humano al agua y saneamiento, el desarrollo conceptual se remonta a una conferencia desarrollada en Mar del Plata, Argentina (ONU, 1977), donde también se abordó, por primera vez, el concepto de la cantidad básica de agua requerida para satisfacer las necesidades humanas fundamentales.

Es de aclarar que desde la declaración Universal (AGNU, 1948), ya había un reconocimiento incipiente e indirecto, cuando en su artículo veinticinco, se consagró, entre otras cosas que, "toda persona tiene derecho a un nivel de vida adecuado que le asegure, así como a su familia, la salud y el bienestar,y en especial la alimentación". Esto, en razón a que el agua es esencial para el bienestar, no solo para la subsistencia humana, sino para los seres vivos, tanto para la fauna como la flora.

Más adelante, el reconocimiento internacional del acceso al agua potable y saneamiento, derivado del derecho a un nivel de vida adecuado, se incorpora internacionalmente en virtud del Artículo II.I del Pacto Internacional de Derechos Económicos, Sociales y Culturales -PIDES(AGNU, 1967), pero de manera muy específica, en noviembre de 2002, el Comité de Derechos Económicos, Sociales, y Culturales —Comité PIDESC—, adoptó la Observación General número quince, donde establece igualmente, en el art. I.I que "el derecho humano al agua es indispensable para una vida humana digna".

La observación también estableció el derecho de cada uno a disponer de agua suficiente, saludable, aceptable, físicamente accesible y asequible para su uso personal y doméstico. Elementos que hacen parte de los estándares internacionales. Materia que será objeto de estudio en el acápite siguiente. 
Posteriormente, el 28 de julio de 2010, la Asamblea General de la ONU adoptó una resolución pionera — 64/292 - reconociendo que "el derecho al agua potable y el saneamiento es un derecho humano esencial para el pleno disfrute de la vida y de todos los derechos humanos" (AGNU, 20 I0, párr. I). Para el 20I I, además de lo anterior, se estipula que el derecho al agua y al saneamiento está indisolublemente asociado al derecho del más alto nivel posible de salud física y mental, así como al derecho a la vida y la dignidad humana (Consejo de Derechos Humanos, 20II).

Adicionalmente, desde 2015 la Asamblea General de la ONU y el Consejo de Derechos Humanos clarificaron que el derecho al agua potable como el derecho al saneamiento, son derechos humanos que están íntimamente ligados, pero que son distintos entre sí (AGNU, 20I5). Hasta lo expuesto, todavía dichas prerrogativas no aportan una definición y diferencia en cuanto al derecho al agua y al saneamiento.

Puntualmente, se entiende por saneamiento "al sistema destinado a la recolección, transporte, tratamiento, eliminación o reciclado de excretas, y la higiene vinculada a estas cuestiones" (Albuquerque, 20 I4, p. 6). En virtud del derecho humano al saneamiento "toda persona puede acceder a servicios de saneamiento que proporcionen intimidad y garanticen la dignidad y que, sean accesibles desde el punto de vista físico y económico, de calidad, higiénicos, seguros y social y culturalmente aceptable" (Albuquerque, 20I4, p. 6). El derecho humano al saneamiento demanda que los servicios estén disponibles y sean inocuos, aceptables, accesibles y asequibles (Consejo de Derechos Humanos, 20I5, párr. 5).

Adicional a lo descrito, en el marco de la Relatoría Especial sobre el Derecho Humano al Agua Potable y el Saneamiento, en la ONU se ha establecido que,

"los estados deben garantizar, sin discriminación, que toda persona tenga acceso, desde el punto de vista físico y económico, al saneamiento, en todas las esferas de la vida, que sea inocuo, higiénico, seguro, aceptable desde el punto de vista social y cultural, proporcione intimidad y garantice la dignidad. (...) Además del acceso individual a una letrina o retrete, el saneamiento también ocupa una dimensión importante en la salud pública. Un saneamiento adecuado no solo garantiza un acceso individual, sino que también protege los derechos humanos de los demás, incluido su derecho a la vida, la salud, el agua y un medio ambiente sano, velando por que el entorno en el que viven no esté contaminado por las heces (véase A/68/264)" (Consejo de Derechos Humanos, 20I5, párrafos 5-6.).

En cuanto al derecho humano al agua, es indiscutible que el agua es un recurso natural limitado y bien público fundamental para la vida y la salud (ONU, 2003). No es gratuito que sea un derecho humano indispensable para vivir dignamente y conditio sine qua non para la realización de otros derechos humanos. Por ello, es exigible a los estados desde los estándares internacionales 
disponer de agua suficiente, salubre, aceptable, accesible y asequible.

Lo anterior es de una importancia tal "que un abastecimiento adecuado de agua salubre es necesario para evitar la muerte por deshidratación, para reducir el riesgo de las enfermedades relacionadas con el agua y para satisfacer las necesidades de consumo, cocina y las necesidades de higiene personal y doméstica" (ONU, 2003, párrafo 2).

El agua se ha percibido de muchas maneras a lo largo de los años, recibiendo varios calificadores: un recurso de flujo, un bien económico, un recurso público y no sustituible (Salman, 20l4), pero para los efectos de este escrito es un bien social, colectivo y cultural, y no fundamentalmente un bien económico. En el caso específico, como derecho humano el agua abarca dos aspectos fundamentales, por un lado,

"entraña libertades, las cuales están dadas por la protección contra cortes arbitrarios e ilegales; la prohibición de la contaminación ilegal de los recursos hídricos; la no discriminación en el acceso al agua potable y el saneamiento, en particular por razón de la clasificación de la vivienda o de la tierra; la no injerencia en el acceso a los suministros de agua existentes, especialmente las fuentes de agua tradicionales; $y$ la protección contra las amenazas a la seguridad personal al acceder a agua o servicios de saneamiento fuera del hogar" (Alto Comisionado de las Naciones Unidas para los Derechos Humanos, 20I I, p. 8).

Por otra parte, entraña prestaciones, mismas que comprenden:

"el acceso a una cantidad mínima de agua potable para mantener la vida y la salud; el acceso a agua potable y servicios de saneamiento durante la detención; y la participación en la adopción de decisiones relacionadas con el agua y el saneamiento a nivel nacional y comunitario" (Alto Comisionado de las Naciones Unidas para los Derechos Humanos, 20I I, p. 8).

Las políticas centradas en las personas para proveer servicios de agua y saneamiento y una gestión sólida y sostenible de los recursos hídricos y los ecosistemas como un todo son, por tanto, parte integral del desarrollo sostenible y del pleno disfrute de los derechos humanos al agua y el saneamiento (UNESCO, 2019, p. 39).Así como también, de una amplia variedad de otros derechos humanos, incluidos los derechos a la vida, la salud y la alimentación.

Desde esta perspectiva, el abastecimiento de agua potable y el saneamiento se basan en un enfoque protector de los derechos humanos, mismo que proporciona unos principios para hacer frente a la actual crisis del agua y el saneamiento. Este puede y debe utilizarse al estudiar cuestiones más amplias, como la ordenación de los recursos hídricos. Esto, según el Alto Comisionado 
de las Naciones Unidas para los Derechos Humanos (20I I).

En cuando a los principios que emanan del enfoque de los derechos humanos, aparecen en forma de parámetros esenciales o pautas de obligatorio cumplimiento como lo es, el derecho a la información, a la participación, a la rendición de cuentas y el principio de igualdad y no discriminación. Este último, a partir del grupo específico que se analiza en este escrito —indígenas, afrodescendientes y tribales - impone a los estados de la región la reivindicación de adoptar acciones afirmativas.

Obsérvese que, muchas veces la discriminación histórica o profundamente arraigada puede resultar tan difícil de remediar, que se requieren medidas especiales de carácter temporal, llamadas también medidas de discriminación positiva. Cuando las barreras existen y persisten, y conducen a la negación de los derechos de individuos y grupos, se requieren medidas positivas para garantizar la participación igualitaria de todos y la redistribución de poder y recursos a los grupos subordinados por la discriminación (Albuquerque, 20I4). Esta es la razón, entre otras, por la que este artículo se centra en estos grupos.

\section{Estándares internacionales de protección de los derechos humanos sobre el agua y al saneamiento}

Derivado del sistema universal de protección de los derechos humanos en la ONU se han desarrollado unos estándares internacionales como parámetros de obligatorio cumplimiento, en torno a los derechos al agua y saneamiento. Estos constituyen una guía para los estados, en tanto consagran lineamientos que deben cumplirse sin excepción.

Acorde a la Observación General número quince (2002), estos parámetros deben gozar de adecuación, es decir, los elementos del derecho al agua deben ser adecuados a la dignidad, la vida y la salud humana. Lo adecuado del agua no debe interpretarse de forma restrictiva, simplemente en relación con cantidades volumétricas y tecnologías. El agua debe tratarse como un bien social y no como un bien económico.

El modo en que se ejerza el derecho al agua también debe ser sostenible, de manera que este derecho pueda ser ejercido por las generaciones actuales y futuras (ONU, Observación General núm. I5, 2002). Finalmente, también debe incluir los siguientes factores: (I) disponibilidad, (2) calidad, y (3) accesibilidad, todos ellos alineados al (4) principio de igualdad y no discriminación que, para el estudio, se abordará de manera independiente, pero conexo a los anteriores.

La disponibilidad implica que "el abastecimiento de agua de cada persona debe ser continuo y suficiente para los usos personales y domésticos (...)”. La calidad, por otro lado, es un componente que demanda que el agua sea salubre, "y por lo tanto, no ha de contener microorganismos o sustancias químicas o radiactivas que puedan constituir una amenaza para la salud de las personas (...)"; y la accesibilidad,implica que "el agua y las instalaciones y servicios de agua deben ser accesibles para todos, sin discriminación alguna (...)" (ONU, Observación General núm. I5, 2002, párr. II-12). 
La accesibilidad, al mismo tiempo, presenta cuatro dimensiones superpuestas: accesibilidad física, accesibilidad económica, no discriminación y acceso a la información. En cuanto al primer elemento, la accesibilidad exige que,

"el agua y las instalaciones y servicios de agua deben estar al alcance físico de todos los sectores de la población. Debe poderse acceder a un suministro de agua suficiente, salubre y aceptable en cada hogar, institución educativa o lugar de trabajo o en sus cercanías inmediatas. Todos los servicios e instalaciones de agua deben (...) tener en cuenta las necesidades relativas al género, el ciclo vital y la intimidad" (Cfr. ONU. Observación General núm. 15, párr. II-12).

Por su parte, la accesibilidad económica implica que "el agua y los servicios e instalaciones de agua deben estar al alcance de todos. Los costos y cargos directos e indirectos asociados con el abastecimiento de agua deben ser asequibles y no deben comprometer ni poner en peligro el ejercicio de otros derechos reconocidos en el Pacto" (Cfr. ONU. Observación General núm. I5, párr. I I-I2). En cuanto a la no discriminación impone, al mismo tiempo "que el agua y los servicios e instalaciones de agua deben ser accesibles a todos de hecho y de derecho, incluso a los sectores más vulnerables y marginados de la población, sin discriminación alguna por cualquiera de los motivos prohibidos" (Comité de Derechos Humanos, 1989).

Por último, en cuanto al acceso a la información, asume que "la accesibilidad comprende el derecho de solicitar, recibir y difundir información sobre las cuestiones del agua" (ONU. Observación General núm. I5. Párr. II-12). En suma, una mejor comprensión de estos conceptos contribuye a identificar grupos específicos que actualmente están o corren el riesgo de quedarse atrás en términos de acceso a los servicios de agua y saneamiento; al mismo tiempo, también ayuda a resaltar los roles y las responsabilidades para asegurar que todas las personas reciban un trato justo con acceso equitativo a los recursos y oportunidades (UNESCO, 2019).

En el sistema interamericano de derechos humanos, por ejemplo, la Corte Interamericana —Corte IDH—, ha identificado que el principio de igualdad y no discriminación,

"se desprende directamente de la unidad de naturaleza del género humano y es inseparable de la dignidad esencial de la persona, frente a la cual es incompatible toda situación que, por considerar superior a un determinado grupo, conduzca a tratarlo con privilegio, o que, a la inversa, por considerarlo inferior, lo trate con hostilidad, o de cualquier forma lo discrimine del goce de derechos que sí se reconocen a quienes no se consideran incursos en tal situación de inferioridad (...)" (Corte IDH, 28 de agosto de 2002, párr. 45).

Aunque se aclara, que no toda diferenciación de trato constituirá una discriminación, si los criterios para tal diferenciación son razonables y objetivos y lo que se persigue es lograr un 
propósito legítimo (Comité de Derechos Humanos, 1989). Si bien, los derechos humanos al agua y al saneamiento, como otros DESCA, se deben cumplir progresivamente con el tiempo, existen ciertas obligaciones que son de naturaleza inmediata. Una parte importante de tales obligaciones inmediatas es la eliminación de la discriminación (UNESCO, 2019) y, lo ciertos es, aunque se han logrado cambios evidentes, desde la adopción de la Convención Internacional sobre la Eliminación de todas las Formas de Discriminación Racial, en 1965, que no ha sido suficiente.

Las particularidades de las poblaciones afrodescendientes, indígenas y tribales, demandan un conjunto de especificidades, para visibilizar y sanear las necesidades más vitales, entre ellas, las concernientes a los derechos al agua y al saneamiento. Nótese al respecto, que la situación de discriminación estructural se hace palpable en los indicadores de acceso a viviendas, pues muchas de ellas (CIDH, 20II, párr. 46), carecen de agua potable entubada por red pública.

Durante una visita, del Relator sobre los Derechos de los Afrodescendientes y contra la Discriminación Racial de la CIDH (2007), al Estado colombiano, recibió numerosos testimonios de miembros de comunidades afrocolombianas y de organizaciones de la sociedad civil, en el sentido que los afrodescendientes padecen la discriminación derivada del acceso desigual a los servicios básicos, el acceso limitado a las oportunidades de avance social y económico. Lo cual también ha sido reincidente en los países del Caribe Anglófono.

Reconocer estas particularidades debe permitir de manera acertada, eficaz y eficiente, a los distintos gobiernos de la región, cumplir con los estándares emanados del derecho internacional de los derechos humanos, con planes, medidas $y / o$ acciones positivas que respondan a las obligaciones derivadas del principio de igualdad y no discriminación.

\section{Hallazgos}

En la última década, si bien, se ha documentado por diferentes órganos, organismos y organizaciones internacionales, avances notorios en cuanto al acceso al agua potable y saneamiento, se observó que las brechas de pobreza y pobreza extrema, es un continuum en las subregiones y en ciertos estados, más que en otros, hecho que impide cumplir con los estándares emanados del derecho internacional de los derechos humanos en las Américas.

También se puede observar que los derechos al agua y saneamiento, aunque ligados entre sí, son independientes y gozan de un andamiaje jurídico propio, pero pese a su reciente evolución, todavía la pretensión de la universalidad es un ideal, en tanto que, no son accesibles para todas las personas en el continente americano. La situación de las personas afrodescendientes, indígenas y tribales en las Américas, es una fiel prueba de ello. Contexto en el cual, países avanzados como EEUU tampoco se salvan de este desafortunado balance.

También se observó, concluyentemente, que el auge en la demanda internacional de bienes primarios ha detonado una economía del extractivismo depredadora de los recursos naturales, a costa de un número significativo de conflictos ambientales, sociales y étnicos.

Específicamente, se encontró una estrecha relación entre extractivismo, poblaciones 
afrodescendientes, indígenas y tribales en la región, situando algunos pueblos, incluso, en peligro de extinción, coyuntura que se concentra, en mayor medida, en el contexto rural, más que el urbano. Este escenario afecta tanto a poblaciones afrodescendientes, como a tribus indígenas, pues sus "sistemas de valores, conocimientos y prácticas únicas han sido ignoradas en los procesos de visión de los recursos del agua" (Nakashima y Chiba, 2007, p. 12).

Otro hallazgo importante es la falta de consulta previa libre e informada de los respectivos gobiernos, en la región, pese al reconocimiento expreso por el Convenio I69 de la OIT, como prerrogativa exclusiva para pueblos indígenas y tribales, por tratarse de pueblos culturalmente diferentes.

Es un hecho clave - como coincide con los países en la región- que los pueblos indígenas se ubican entre los más pobres y en zonas donde el acceso a los servicios básicos, como el agua potable, es más precario en relación con el resto de la población. Coyuntura que obliga a los estados en la región a desarrollar políticas, planes y estrategias específicas relativas al derecho al agua y el saneamiento, atendiendo a medidas positivas o de acciones afirmativas.

Por tal razón, se demandan medidas coherentes al robusto conjunto de argumentos legales y jurisprudenciales (Galeano, 20l3) existentes, en el corpus iuris internacional, que es lo suficientemente amplio, para asegurar el goce efectivo tanto del derecho al agua como del saneamiento.

Aunque en las Américas la situación de los estados es ampliamente heterogénea, cultural, poblacional y económicamente, es necesario que las políticas gubernamentales en el ámbito regional también dialoguen con la sociedad civil, pues estás son cruciales para reducir la degradación y contaminación ambiental; de la mano de un marco de gestión integrada de calidad para los recursos hídricos. En la medida que la carencia de agua potable y saneamiento está generando en las Américas que población vulnerable y excluida históricamente, muera cada año, precisamente por enfermedades asociadas al agua, esto sin contar, con la contaminación de los ríos por procesos extractivos, como la minería.

Finalmente, si bien las cifras destacadas no pueden identificar a priori que personas afrodescendientes, indígenas y tribales, conviven en contextos de discriminación, la situación es per se, manifestación clara de las condiciones de pobreza y pobreza extrema como rasgo característico en estas poblaciones. Pero si puede decirse, no obstante, que en algún punto estructural el análisis puede cruzarse con la posición socioeconómica desfavorable y la discriminación étnica, hecho que, en últimas es un indicador clave en la regresividad de los derechos económicos, sociales, culturales y ambientales en la región.

\section{Referencias}

ACNUDH (2018). Derecho al agua. Folleto informativo número 35. Alto Comisionado de las Naciones Unidas para los Derechos Humanos. Recuperado de: http://acnudh.org/el-derecho-al-agua-folleto-informativo-no-35/ (0I.09.2020).

ACNUR (1989). No discriminación. Observación General 18. Oficina del Alto Comisionado para los Derechos Humanos. Recuperado de: https://www.acnur.org/fileadmin/Documentos/BDL/200I//404.pdf (01.09.2020). 
AGNU (1948). Declaración Universal de los Derechos Humanos. Resolución 217 A (III). Asamblea General de las Naciones Unidas. Recuperado de: https://www.un.org/es/universal-declaration-human-rights/ (0I.09.2020).

AGNU (2015). Los derechos humanos al agua potable y el saneamiento. Resolución A/RES/70/I69, aprobada por la Asamblea General el 17 de diciembre de 2015. Recuperado de: https://undocs.org/es/A/RES/70/I69 (0I.09.2020)

Albuquerque, C. D. (20I4). Manual prático para la realización de los derechos humanos al agua y al saneamiento de la Relatora Especial de la ONU. Portugal.

Banco Mundial (2018). Afrodescendientes en Latinoamérica: Hacia un marco de inclusión. Recuperado de: https://openknowledge.worldbank.org/bitstream/handle/ I0986/3020 I// 29298-7-8-20 I 8- | 7-30-5 I AfrodescendientesenLatinoamerica.pdf?sequence=5\&isAllowed=y (0I.09.2020).

Berger, D. N. (2019). El Mundo Indígena 2019. Grupo Internacional de Trabajo sobre Asuntos Indígenas. Recuperado de: $\quad$ https://www.iwgia.org/images/documentos/indigenous-world-esp/EIMundolndigena2019_ES.pdf (0l.09.2020).

Bertoméu-Sánchez, S. y Serebrisky,T. (2018).Water and Sanitation in Latin America and the Caribbean:An Update on the State of the Sector. (R. S. Studies, Ed.) Robert Schuman Centre for Advanced Studies Working Papers, I-28. DOI: |0.2139/ssrn.3157|43

Brackmann, S., Ducci, J., Garzón, c., Nuques, C., Perroni, A., Bouzerma, D., Matthieussent R., Rodríguez-Pérez, A. y Etienne, M. (2009). Haití. Proyecto de agua y saneamiento para Puerto Príncipe. Puerto Príncipe: Banco Interamericano de Desarrollo y Fondo Español de Cooperación para Agua y Saneamiento en América Latina y el Caribe. Recuperado de: https://www.aecid.es/Centro-Documentacion/Documentos/FCAS/Proyectos/ POD/HTI-004-M_POD.PDF (0I.09.2020).

Calderón, C., Núñez, A., y Wanner, Z. (2018). Introduction:Water and Sanitation in Latin America and the Caribbean. En Calderón, C., Núñez, A. y Wanner, Z. (Eds.), Speaking of water. Digital conversation on water and sanitation in Latin America and the Caribbean (20l6-20l 7) (pp. I-53). Inter-American Development Bank.

Castaño, A. (2015). Palenques y Cimarronaje: procesos de resistencia al sistema colonial esclavista en el Caribe Sabanero (Siglos XVI, XVII y XVIII). Revista CS (I6), 6I-86. DOI: https://doi.org/ I0.18046/recs.i I6.2024.

Castro, J. (16.II.2018). Fracking o fracturación hidráulica y el Lote 192. Comunicación intercultural para un mundo más humano y diverso. Recuperado de: https://www.servindi.org/actualidad-noticias//5// I/20/8/fracking-y-ellote-192. (01.09.2020).

CEDAW (1979). Convención sobre la Eliminación de todas las formas de Discriminación contra la Mujer. Recuperado de: www.un.org/womenwatch/daw/cedaw/text/econvention.htm\#intro (01.09.2020).

CEPAL (20I3). Lineamientos para incluir la identificación de pueblos indígenas y afrodescendientes en los registros de salud. Recuperado de: https://repositorio.cepal.org/bitstream/handle/II362/35952/I/S20I3I049 es.pdf (0I.09.2020).

CEPAL (20I4). Los pueblos indígenas en América Latina:Avances en el último decenio y retos pendientes para la garantía de sus derechos. Recuperado de: https://repositorio.cepal.org/bitstream/handle/I I362/37050/4/SI420783 es.pdf (0I.09.2020).

CEPAL (2017). Situación de las personas afrodescendientes en América Latina y desafios de políticas para la garantía de sus derechos. Recuperado de: https://repositorio.cepal.org/bitstream/handle/II362/42654/I/SI70I063_es.pdf (0I.09.2020).

CEPAL (2019). Panorama Social de América Latina, 20/8. Recuperado de: https://repositorio.cepal.org/bitstream/ handle/ I I362/44395/I I/SI 90005 I es.pdf (01.09.2020).

CIDH (2007). Visita del Relator para los Derechos de los Afrodescendientes y contra la Discriminación Racial a la República de Colombia. Recuperado de: http://www.cidh.oas.org/countryrep/ColombiaAfrodescendientes.sp/ ColombiaAfros2009cap3-4.sp.htm. (01.09.2020).

$\mathrm{CIDH}$ (20lI). Situación de los derechos humanos de las personas afrodescendientes en las Américas. Recuperado de: https://www.oas.org/es/cidh/prensa/comunicados/20I2/005.asp (0I.09.2020).

CIDH (20I5). Informe sobre el I 56 Período de Sesiones de la CIDH. Recuperado de: http://www.oas.org/es/cidh/prensa/ comunicados/2015/I20A.asp. (01.09.2020).

$\mathrm{CIDH}$ (2017). Informe sobre pobreza y derechos humanos en las Américas. Recuperado de: http://www.oas.org/es/cidh/ informes/pdfs/PobrezaDDHH20I7.pdf. (0I.09.2020).

CIDH (2019). Situación de los derechos humanos de los pueblos indígenas y tribales de la Panamazonía. Recuperado de: http://www.oas.org/es/cidh/informes/pdfs/Panamazonia20 I9.pdf (01.09.2020).

Consejo de Derechos Humanos (20II). Promoción y protección de todos los derechos humanos, civiles, políticos, económicos, sociales y culturales, incluido el derecho al desarrollo. Resolución A/HRC/RES/ I8/I.Asamblea General de las Naciones Unidas. Recuperado de: https://www.acnur.org/fileadmin/Documentos/BDL/2008/60 17.pdf (0I.09.2020).

Consejo de Derechos Humanos (2015). El derecho humano al agua potable y el saneamiento. Cuestiones de derechos humanos, incluidos otros medios de mejorar el goce efectivo de los derechos humanos y las libertades fundamentales. Resolución A/70/203, Asamblea General de las Naciones Unidas. Recuperado de: https://www.acnur.org/ fileadmin/Documentos/BDL/20I5/I0I49.pdf (0I.09.2020).

Corte Interamericana de Derechos Humanos (28 de agosto de 2002). Condición jurídica y derechos humanos del niño. OC-I 7/02. Serie A No. 17. Recuperado de: https://www.corteidh.or.cr/docs/opiniones/seriea_I7_esp. 
pdf (0I.09.2020).

Department of Economic and SocialAffairs of the United Nations (20I5). State of theWorld's Indigenous Peoples: Indigenous Peoples' access to Health Services. Recuperado de: https://www.un.org/development/desa/indigenouspeoples/ wp-content/uploads/sites/I 9/2018/03/The-State-of-The-Worlds-Indigenous-Peoples-WEB.pdf (01.09.2020).

Food and Agriculture Organization of the United Nations. (s.f.). Suriname and FAO. Partnering for Sustainable Food and Agricultural. Recuperado de: http://www.fao.org/3/AZ420E/az420e.pdf (01.09.2020).

Galeano, F.(20I3). Protección constitucional del derecho al agua: el caso colombiano. Anuario de Derechos Humanos, (9), 89-99. DOI: | 0.5354/07| 8-2279.20|3.27034.

Gentes, I. (2002). Derecho de Agua y Derecho Indígena. Hacia un reconocimiento estructural de la gestión indígena del agua en las legislaciones nacionales de los Países Andinos. Revista de Derecho Administrativo Económico (8), 8I-I I I. DOI: http://dx.doi.org/I0.7764/redae.8.7.

Gertner, G. (2016). Expandiendo acceso al agua potable y saneamiento en pequeñas comunidades rurales de Bolivia: resultados de la Encuesta de Línea de Base de una Evaluación de Impacto Experimental. Banco Interamericano de Desarrollo, División de Agua y Saneamiento. Recuperado de: https://publications.iadb.org/es/publicacion/I5663/ expandiendo-acceso-agua-potable-y-saneamiento-en-pequenas-comunidades-rurales (0I.09.2020).

JMP, OMS, y UNICEF (2016). Saneamiento y agua potable en América Latina y el Caribe. Una perspectiva regional basada en datos del Programa Conjunto de Monitoreo de OMS/UNICEF del Abastecimiento de Agua y del Saneamiento y un análisis de la desigualdad a partir de encuestas nacionales de hogares y censos recientes. Recuperado de: https:// www.unicef.org/lac/informes/desigualdades-en-materia-de-saneamiento-y-agua-potable-en-am\%C3\%A9ricalatina-y-el-caribe (0I.09.2020).

Langford, M. (2005). The United Nations Concept of Water as a Human Right: A New Paradigm for Old Problems?. International Journal of Water Resources Development, 2I(2), 273-282. DOI: https://doi. org/l0.1080/07900620500035887.

Nakashima, D. y Chiba, M. (2007). El Agua y los pueblos indígenas. Paris: UNESCO.

National Geographic (s.f.). ¿Cuántos pueblos indígenas hay en América Latina?. Recuperado de: https://www.ngenespanol. com/traveler/cuantos-pueblos-indigenas-hay-en-america-latina/ (I 9.02.2020).

OIT (1989). Convenio sobre pueblos indígenas y tribales en países independientes. Recuperado de: http://www.ilo.org/dyn/ normlex/es/f?p=NORMLEXPUB: | 2 | 00:0::NO::PI 2 I00 INSTRUMENT ID:3 I 23 | 4 (01.09.2020)

ONU (1977). Plan de Acción de Mar del Plata, Conferencia de las Naciones Unidas sobre el Agua. Recuperado de: file:///C:/Users/HP/Downloads/Plan\%20de\%20Acci\%C3\%B3n\%20MdP-BID.pdf (02.09.2020).

ONU (2002). Cuestiones Sustantivas que se plantean en la aplicación del Pacto Internacional de Derechos Económicos, Sociales y Culturales. Observación General N I5. Comité de Derechos Económicos, Sociales y Culturales. Recuperado de: http://www.derechos.org.ve/pw/wp-content/uploads/ObsGral I 5I.pdf (0I.09.2020).

ONU (20l0). El derecho humano al agua y el saneamiento. Asamblea General de Naciones Unidas, A/RES/64/292. Recuperado de: https://www.un.org/ga/search/view_doc.asp?symbol=A/RES/64/292\&Lang=S (0I.09.2020).

Organización Mundial de la Salud (2006). Guías para la calidad del agua potable. Recuperado de: https://www.who.int/ water_sanitation_health/dwq/gdwq3_es_fulll_lowsres.pdf (0l.09.2020).

Organización Panamericana de la Salud y Organización Mundial de la Salud (1997). Fortalecimiento y Desarrollo de los Sistemas de Salud Tradicionales: Organización y Provisión de Servicios de Salud en Poblaciones Multiculturales. Iniciativa de Salud de los Pueblos Indígenas. Recuperado de: https://www.paho.org/hq/dmdocuments/2009/I0Esp\%20IND6.pdf (0I.09.2020)

Organización Panamericana de la Salud (s.f.). Belice. Recuperado de: https://www.paho.org/salud-en-las-americas2017/?post_t_es=belice\&lang=es (20.02.2020)

Organización Panamericana de la Salud (s.f.). Jamaica. Recuperado de: https://www.paho.org/salud-en-las-americas2017/?post_t_es=jamaica\&lang=es (20.02.2020).

Parellada, A. (2019). México y América Central. En Berger, D.N. (Comp.). El mundo indígena 2019, (pp. 89-90). Copenhague: Grupo Internacional de Trabajo sobre Asuntos Indígenas.

PNUD (2006). Informe sobre Desarrollo Humano 2006. Más allá de la escasez: poder, pobreza y la crisis mundial del agua. Recuperado de: http://hdr.undp.org/sites/default/files/hdr_2006_es_completo.pdf (0I.09.2020).

Procuraduría para la Defensa de los Derechos Humanos (2012). Derechos Humanos de las poblaciones afrodescendientes. Recuperado de: https://centroderecursos.cultura.pe/sites/default/files/rb/pdf/Derechoshumanos-de-las-poblaciones-afrodescendientes-Modulo-de-capacitacion-final.pdf (0I.09.2020).

Programa de Justicia Global y Derechos Humanos (2009). Discriminación racial en Colombia: informe alterno ante el Comité para la Eliminación de la Discriminación Racial de la ONU. Bogotá: Universidad de los Andes.

Quiroz, R., y Quiroz, E. (Edits.) (2008). CAUDAL, Revista Intersectorial de Agua y Saneamiento(7), 6-32. Recuperado de: https://issuu.com/fondoquiroz/docs/informe disponibilidad de agua (01.09.2020).

Riggs, E., Hughes, J., Irvin, D. y Leopard, K. (2017). An Overview of Clean Water Access Challenges in the United States. Chapel Hill: Environmental Finance Center.

Rojas Ortuste, F. (20I4). Políticas e institucionalidad en materia de agua potable y saneamiento en América Latina y el Caribe. Recuperado de: https://repositorio.cepal.org/bitstream/handle/II362/36776/I/S20I4277_es.pdf (0I.09.2020)

Salman, S. M. (20I4). The human right to water and sanitation: is the obligation deliverable? Water International, 39 (7), 969-982. DOI: 10.1080/02508060.2015.9866/6 
UNESCO (2019). Informe Mundial de las Naciones Unidas sobre el desarrollo de los recuros hidricos 2019. No dejar a nadie atrás. Recueprado de: https://unesdoc.unesco.org/ark:/48223/pf0000367304 (01.09.2020).

Vasquez Ochoa, O.Y., Roa Fuentes, C., Torres Rodríguez, G., Salgado Bonnet, J. y Sánchez Peña, N. (2019). Efectos de la actividad minera sobre los recursos hidrobiológicos. Recueprado de: http://www.humboldt.org.co/images/ documentos/2-diagnstico-actividad-minera-y-explotacin-ilicita-expertos.pdf. (0I.09.2020).

Wade, P. (2008). Población negra y la cuestión identitaria en América Latina. Universitas humanística, 65 (65), I I 7 - 137. Recuperado de: http://www.scielo.org.co/pdf/unih/n65/n65a07.pdf (0I.09.2020).

Wessendorf, K. (2019). El mundo indígena 2019. En Berger, D. N. (Comp.), El Mundo Indígena 2019. Copenhague: Grupo Internacional de Trabajo sobre Asuntos Indígenas.

Yamin, A. E. (2006). La defensa y promoción de los derechos económicos, sociales y culturales en América Latina: abramos puertas. En A. E. Yamin, Derechos económicos, sociales y culturales en América Latina. Del invento a la herramienta (pp. 17-42). Ottawa: Centro Internacional de Investigaciones para el Desarrollo.

Zapata Webb, Y. H. (s. f.). Manual de educación ciudadana intercultural y autonómica. Módulo 2. Una historia diferente. Apuntes básicos sobre la historiografia de los pueblos indígenas y las comunidades étnicas de las regiones autónomas de la costa caribe nicaragüense. Recueprado de: https://observatorio.uraccan.edu.ni/manual-de-educacionciudadana-intercultural-y-autonomia (01.09.2020). 


\section{RELACIONES INTERNACIONALES}

Revista académica cuatrimestral de publicación electrónica

Grupo de Estudios de Relaciones Internacionales (GERI)

Universidad Autónoma de Madrid, España

https://revistas.uam.es/relacionesinternacionales

ISSN 1699 - 3950

f facebook.com/RelacionesInternacionales

3. twitter.com/RRInternacional 